\title{
THE CHAOTIC GROWTH MODEL OF THE TOTAL CONSUMPTION VISITOR EXPENDITURE: EURO AREA
}

\author{
Vesna Jablanovic ${ }^{1}$
}

DOI: https://doi.org/10.31410/tmt.2019.17

\begin{abstract}
This paper examines the total consumption expenditure made by a visitor or on behalf of a visitor for and during his/her trip and stay at destination in the euro area. The basic aims of this paper are: firstly, to create a relatively simple chaotic growth model of the total consumption visitor expenditure that is capable of generating stable equilibria, cycles, or chaos, and secondly, to analyze the total consumption visitor expenditure growth stability in the period 2012-2018 in the euro area. This paper confirms the existence of the different growth path of the total consumption visitor expenditure in the euro area in the observed period.
\end{abstract}

Keywords: Expenditure, Tourism, Growth, Stability, Chaos.

\section{INTRODUCTION}

$\mathrm{T}$ he euro was first introduced in 1999. The eurozone consists of the following EU Member States (19) which have adopted the euro as their single currency: Austria, Belgium, Cyprus (2008), Estonia (2011), Finland, France, Germany, Greece (2001), Ireland, Italy, Latvia (2014), Lithuania (2015), Luxemburg, Malta (2008) Netherlands, Portugal, Slovakia (2009), Slovenia (2007), and Spain. The euro has a special impact on the tourism sector. (Jablanovic, 2018, pp. 703).

This paper uses the elements of chaos theory. Namely, chaos theory started with Lorenz's (1963) discovery of complex dynamics arising from three nonlinear differential equations leading to turbulence in the weather system. Li and Yorke (1975) discovered that the simple logistic curve can exhibit very complex behaviour. Further, May (1976) described chaos in population biology. Chaos theory has been applied in economics by Benhabib and Day $(1981,1982)$, Day $(1982,1983$, 1992, 1997.), Grandmont (1985), Goodwin (1990), Medio (1993,1996), Lorenz (1993), Jablanovic (2011, 2013, 2016, 2018), among many others.

The basic aims of this paper are: firstly, to create a relatively simple chaotic growth model of the total consumption visitor expenditure that is capable of generating stable equilibria, cycles, or chaos. On the other hand, it is important to analyze the total consumption visitor expenditure growth stability in the period 2012-2018. in the euro area. This paper confirms the existence of the different growth path of the total consumption visitor expenditure in the euro area in the observed period.

\section{THE MODEL}

The chaotic total consumption visitor expenditure growth model is presented by the following equations:

$$
\mathrm{Y}_{\mathrm{t}}=\mathrm{C}_{\mathrm{t}}+\mathrm{I}_{\mathrm{t}}+\mathrm{G}_{\mathrm{t}}+\mathrm{Nx}_{\mathrm{t}}
$$

\footnotetext{
University of Belgrade, Faculty of Agriculture, Nemanjina 6, 11081 Belgrade, Republic of Serbia
} 


$$
\begin{aligned}
& \mathrm{C}_{\mathrm{t}}=\alpha \mathrm{Y}_{\mathrm{t}-1}{ }^{2} 0<\alpha<1 \\
& \mathrm{I}_{\mathrm{t}}=\beta \mathrm{Y}_{\mathrm{t}-1} 0<\beta<1 \\
& G_{t}=g Y_{t} 0<g<1 \\
& \mathrm{Nx}_{\mathrm{t}}=\gamma \mathrm{Y}_{\mathrm{t}-1} 0<\gamma<1 \\
& \mathrm{E}_{\mathrm{t}}=\varepsilon \mathrm{Y}_{\mathrm{t}} 0<\varepsilon<1
\end{aligned}
$$

with $\mathrm{Y}$ - the gross domestic product (GDP), I - investment, C- consumption, $\mathrm{Nx}$ - net exports, $\mathrm{G}-$ government spending, $\mathrm{E}-$ the total consumption visitor expenditure, $\alpha-$ the marginal propensity to consume, $\beta$ - the investment rate, g- the government expenditure rate, $\gamma$ - the net exports rate, $\varepsilon-$ the total consumption visitor expenditure rate.

(1) GDP (Y) is the sum of consumption (C), investment (I), government spending (G), and net exports $(\mathrm{Nx})$;

(2) the consumption function displays the quadratic relationship between consumption (Ct) and real output of the previous period $\left(\mathrm{Y}_{\mathrm{t}-1}\right)$, where the coefficient $\alpha$ is ,the marginal propensity to consume“ (MPC) . The MPC coefficient can be between zero and one.

(3) shows the investment function;

(4) shows the relation between government spending $(\mathrm{G})$ and the gross domestic product (Y); (5) shows the relation between net exports $(\mathrm{Nx})$ and the gross domestic product $(\mathrm{Y})$;

Finally, (6) explains the relation between the total consumption visitor expenditure (E) and the gross domestic product (Y).

Now, putting (1), (2), (3), (4), (5), and (6) together we immediately get:

$$
\mathrm{E}_{\mathrm{t}+1}=\left(\frac{\beta+\gamma}{1-g}\right) E_{t-1}+\left[\frac{\alpha}{\varepsilon(1-g)}\right] E_{t-1}^{2}
$$

Further, it is assumed that the current value of the total consumption visitor expenditure is restricted by its maximal value in its time series. This premise requires a modification of the growth law. Now, the total consumption visitor expenditure growth rate depends on the actual value of the total consumption visitor expenditure, E, relative to its maximal size in its time series Em. We introduce e as $\mathrm{e}=\mathrm{E} / \mathrm{E}^{\mathrm{m}}$. Thus, $\mathrm{E}$ range between 0 and 1 . Again we index e by $t$, i.e. write $e_{t}$ to refer to the size at time steps $t=0,1,2,3, \ldots$ Now the total consumption visitor expenditure growth rate is measured as

$$
\mathrm{e}_{t+1}=\left(\frac{\beta+\gamma}{1-g}\right) e_{t-1}+\left[\frac{\alpha}{\varepsilon(1-g)}\right] e_{t-1}^{2}
$$

This model given by equation (8) is called the logistic model. For most choices of $\alpha, \beta, \gamma, \varepsilon$, and $g$ there is no explicit solution for (8). Namely, knowing $\alpha, \beta, \gamma, \varepsilon$, and $g$ and measuring $\mathrm{e}$ ${ }_{0}$ would not suffice to predict $\mathrm{e}_{\mathrm{t}}$ for any point in time, as was previously possible. This is at the heart of the presence of chaos in deterministic feedback processes. Lorenz (1963) discovered this effect - the lack of predictability in deterministic systems. Sensitive dependence on initial conditions is one of the central ingredients of what is called deterministic chaos. 


\section{THE LOGISTIC EQUATION}

It is possible to show that iteration process for the logistic equation

$$
\mathrm{z}_{\mathrm{t}+1}=\eta \mathrm{z}_{\mathrm{t}}\left(1-\mathrm{z}_{\mathrm{t}}\right), \eta \in[0,4], \mathrm{z}_{\mathrm{t}} \in[0,1]
$$

is equivalent to the iteration of growth model (8) when we use the identification

$$
\mathrm{Zt}=-\left[\frac{\alpha}{\varepsilon(\beta+\gamma)}\right] e_{t} \text { and } \eta=\left(\frac{\beta+\gamma}{1-g}\right)
$$

Using (8) and (10) we obtain:

$$
\begin{aligned}
& z_{t}=-\left[\frac{\alpha}{\varepsilon(\beta+\gamma)}\right] e_{t}=-\left[\frac{\alpha}{\varepsilon(\beta+\gamma)}\right]\left\{\left(\frac{\beta+\gamma}{1-g}\right) e_{t-1}+\left[\frac{\alpha}{\varepsilon(1-g)}\right] e_{t-1}{ }^{2}\right\}= \\
& =-\left[\frac{\alpha}{\varepsilon(1-g)}\right] e_{t-1}-\left[\frac{\alpha^{2}}{\varepsilon^{2}(\beta+\gamma)(1-g)}\right] e_{t-1}{ }^{2}
\end{aligned}
$$

On the other hand, using (9) and (10) we obtain:

$$
\begin{aligned}
& \mathrm{z}_{\mathrm{t}+1}=\eta \mathrm{z}_{\mathrm{t}}\left(1-\mathrm{z}_{\mathrm{t}}\right) \\
& z_{t}=-\left(\frac{\beta+\gamma}{1-g}\right)\left[\frac{\alpha}{\varepsilon(\beta+\gamma)}\right] e_{t-1}\left\{1-\left[\frac{\alpha}{\varepsilon(\beta+\gamma)}\right] e_{t-1}\right\}= \\
& =-\left[\frac{\alpha}{\varepsilon(1-g)}\right] e_{t-1}-\left[\frac{\alpha^{2}}{\varepsilon^{2}(\beta+\gamma)(1-g)}\right] e_{t-1}^{2}
\end{aligned}
$$

Thus, we have that iterating (8) is really the same as iterating (9) using (10). It is important because the dynamic properties of the logistic equation (9) have been widely analyzed (Li and Yorke (1975), May (1976)).

It is obtained that:

(i) For parameter values $0<\eta<1$ all solutions will converge to $\mathrm{z}=0$;

(ii) For $1<\eta<3,57$ there exist fixed points the number of which depends on $\eta$;

(iii) For $1<\eta<2$ all solutions monotonically increase to $z=(\eta-1) / \eta$;

(iv) For $2<\eta<3$ fluctuations will converge to $\mathrm{z}=(\eta-1) / \eta$;

(v) For $3<\eta<4$ all solutions will continuously fluctuate;

(vi) For 3,57< $\eta<4$ the solution become ,chaotic" which means that there exist totally aperiodic solution or periodic solutions with a very large, complicated period. This means that the path of $\mathrm{z}_{\mathrm{t}}$ fluctuates in an apparently random fashion over time, not settling down into any regular pattern whatsoever.

\section{EMPIRICAL EVIDENCE}

The main aim of this paper is to analyze the total consumption visitor expenditure growth stability in the period 2012-2018. in the euro area (see Figures 1-5). 
In this sense, it is important to use the logistic model (11):

$$
\mathrm{e}_{\mathrm{t}+1}=\eta \mathrm{e}_{\mathrm{t}}+\mathrm{v} \mathrm{e}_{\mathrm{t}}{ }^{2}
$$

where $\mathrm{e}-$ the total consumption visitor expenditure, $\eta=\left(\frac{\beta+\gamma}{1-g}\right), v=[\alpha / \varepsilon(1-\mathrm{g})]$.

Now, the model (11) is estimated (see Tables 1-19.).

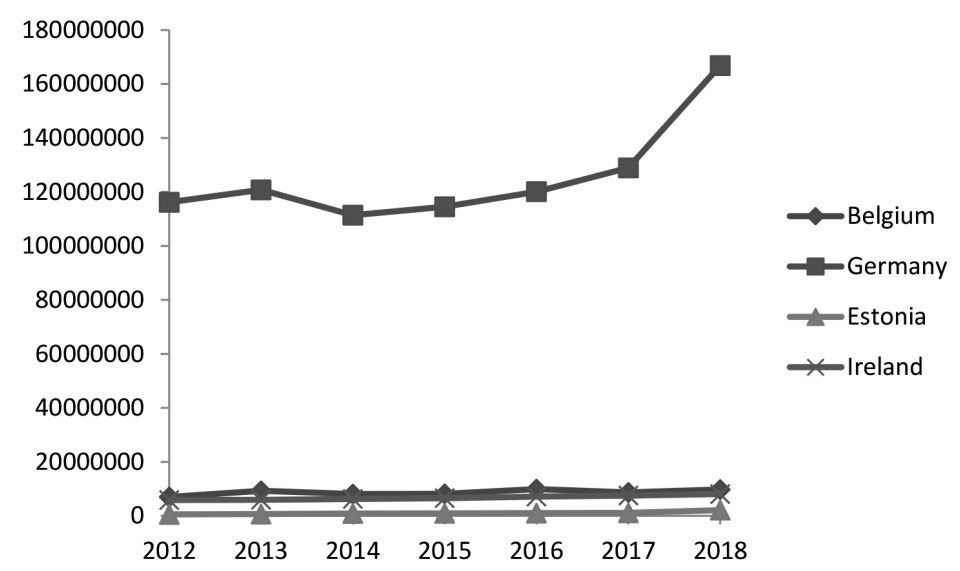

Figure 1. The total consumption expenditure made by a visitor or on behalf of a visitor for and during his/her trip and stay at destination (thousand euro): Belgium, Germany, Estonia, Ireland, 2012-2018.

Source: https://ec.europa.eu/eurostat/databrowser/view/tin00194/default/table?lang=en

Table 1. The estimated model (11): Germany, 2012-2018.

$\mathrm{R}=0.83335$ Variance explained: $69.447 \%$

\begin{tabular}{|l|r|r|}
\cline { 2 - 3 } \multicolumn{1}{c|}{} & \multicolumn{1}{c|}{$\boldsymbol{\eta}$} & \multicolumn{1}{c|}{$\boldsymbol{v}$} \\
\hline Estimate & -0.613071 & 2.36303 \\
\hline Std. Err. & .900806 & 1.25964 \\
\hline $\mathbf{t}(\mathbf{4})$ & -0.680580 & 1.87595 \\
\hline $\mathbf{p}$-level & .533493 & .13391 \\
\hline
\end{tabular}

Table 2. The estimated model (11): Belgium, 2012-2018.

$\mathrm{R}=0.35161$ Variance explained: $12.363 \%$

\begin{tabular}{|l|r|r|}
\cline { 2 - 3 } \multicolumn{1}{c|}{} & \multicolumn{1}{c|}{$\boldsymbol{\eta}$} & \multicolumn{1}{c|}{$\boldsymbol{v}$} \\
\hline Estimate & 2.370477 & -1.561966 \\
\hline Std. Err. & .614352 & .668449 \\
\hline $\mathbf{t}(\mathbf{4})$ & 3.858499 & -2.336702 \\
\hline $\mathbf{p}$-level & .01817 & .079665 \\
\hline
\end{tabular}

The total consumption visitor expenditure fluctuated between 6986821.99 and 9912538.26 (unit of measure: Thousand euro) in the period 2012-2018 in Belgium.

According to the logistic equation, for $2<\eta<3$ fluctuations converge to $z=(\eta-1) / \eta$, or $(2.370477-1) / 2.370477=0.578144$.

According to (10.), the equilibrium value of the total consumption visitor expenditure was $0.578144 /(1.561966 / 2.370477)$ or $0.578144 / 0.658925$ or 0.87704 or 8693692.55 (unit of measure: Thousand euro) in Belgium in the observed period. 
Table 3. The estimated model (11): Estonia,2012-2018.

$\mathrm{R}=0.82099$ Variance explained: $67402 \%$

\begin{tabular}{|l|r|r|}
\cline { 2 - 3 } \multicolumn{1}{c|}{} & \multicolumn{1}{c|}{$\boldsymbol{\eta}$} & \multicolumn{1}{c|}{$\boldsymbol{v}$} \\
\hline Estimate & 0.360214 & 2.20901 \\
\hline Std. Err. & .876269 & 1.95004 \\
\hline t(4) & 0.411077 & 1.13280 \\
\hline p-level & .702086 & .32060 \\
\hline
\end{tabular}

An estimated value of the coefficient $\eta(0.360214)$ describes convergent movement of the total consumption expenditure made by a visitor in Estonia in the observed period.

Table 4. The estimated model (11): Ireland, 2012-2018.

$\mathrm{R}=0.98680$ Variance explained: $97.377 \%$

\begin{tabular}{|l|r|r|}
\cline { 2 - 3 } \multicolumn{1}{c|}{} & \multicolumn{1}{c|}{$\boldsymbol{\eta}$} & \multicolumn{1}{c|}{$\boldsymbol{v}$} \\
\hline Estimate & 0.918635 & -.246941 \\
\hline Std. Err. & .097907 & .117862 \\
\hline t(4) & 9.382779 & -2.095173 \\
\hline p-level & .000719 & .22749 \\
\hline
\end{tabular}

An estimated value of the coefficient $\eta$ (0.918635) describes convergent movement of the total consumption expenditure made by a visitor in Ireland in the observed period.

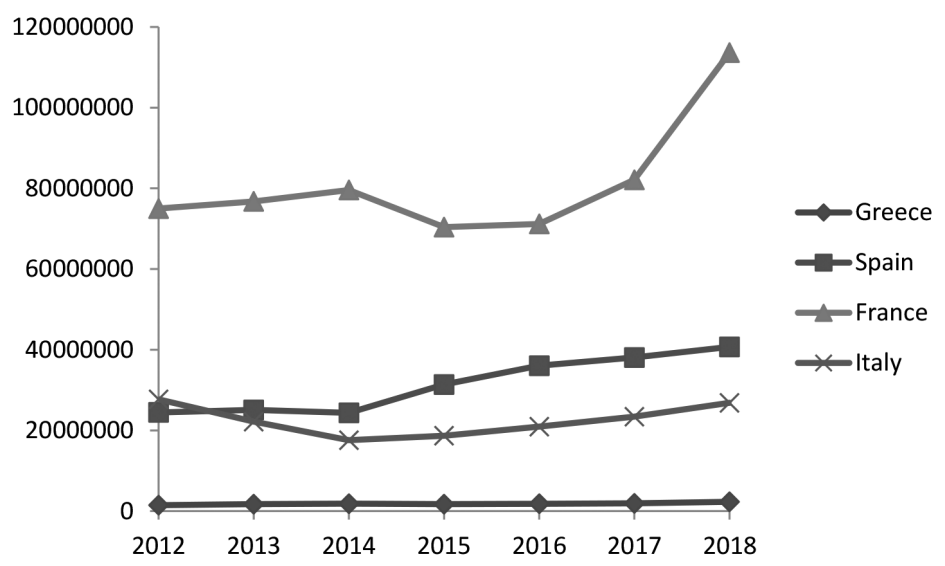

Figure 2. The total consumption expenditure made by a visitor or on behalf of a visitor for and during his/her trip and stay at destination (thousand euro): Greece, Spain, France, Italy, 2012-2018.

Source : https://ec.europa.eu/eurostat/databrowser/view/tin00194/default/table?lang=en

Table 5. The estimated model (11): Greece, 2012-2018.

$\mathrm{R}=0.66256$ Variance explained: $43.898 \%$

\begin{tabular}{|l|r|r|}
\cline { 2 - 3 } \multicolumn{1}{c|}{} & \multicolumn{1}{c|}{$\boldsymbol{\eta}$} & \multicolumn{1}{c|}{$\boldsymbol{v}$} \\
\hline Estimate & 1.174606 & -.12454 \\
\hline Std. Err. & .568429 & .738438 \\
\hline $\mathbf{t}(4)$ & 2.066401 & -.168653 \\
\hline p-level & .107668 & .874254 \\
\hline
\end{tabular}

The total consumption visitor expenditure fluctuated between 1459330,43 and 2294115,65 (unit of measure: Thousand euro) in the period 2012-2018 in Greece. 
According to the logistic equation, for $1<\eta<2$ all solutions monotonically increase to $\mathrm{z}=(\eta-1) / \eta$, or $(1.174606-1) / 1.174606=0.148651$.

According to (10.), the value of the total consumption visitor expenditure monotonically increases to $0.148651 /(0.12454 / 1.174606)$ or $0.148651 / 0.106027$ or 1.402011 or 3216375.38 (unit of measure: Thousand euro) in Greece.

Table 6. The estimated model (11): Spain, 2012-2018. $\mathrm{R}=0.91293$ Variance explained: $83.344 \%$

\begin{tabular}{|l|r|r|}
\cline { 2 - 3 } \multicolumn{1}{c|}{} & \multicolumn{1}{c|}{$\boldsymbol{\eta}$} & \multicolumn{1}{c|}{$\boldsymbol{v}$} \\
\hline Estimate & 1.177343 & -.113883 \\
\hline Std. Err. & .243045 & .304451 \\
\hline $\mathbf{t}(\mathbf{4})$ & 4.844126 & -.374061 \\
\hline p-level & .008375 & .727343 \\
\hline
\end{tabular}

The total consumption visitor expenditure was increased from 24347286 to 40695352.53 (unit of measure: Thousand euro) in the period 2012-2018 in Spain.

According to the logistic equation, for $1<\eta<2$ all solutions monotonically increase to $z=(\eta-1) / \eta$, or $(1.177343-1) / 1.177343=0.15063$.

According to (10.), the value of the total consumption visitor expenditure monotonically increases to $0.15063 /(0.113883 / 1.177343)$ or $0.15063 / 0.096729$ or 1.557237 or 63372308.6878 (unit of measure: Thousand euro) in Spain.

Table 7. The estimated model (11): France, 2012-2018. $\mathrm{R}=0.59494$ Variance explained: $35.396 \%$

\begin{tabular}{|l|r|r|}
\cline { 2 - 3 } \multicolumn{1}{c|}{} & \multicolumn{1}{c|}{$\boldsymbol{\eta}$} & \multicolumn{1}{c|}{$\boldsymbol{v}$} \\
\hline Estimate & .060525 & 1.53002 \\
\hline Std. Err. & 1.405109 & 2.08948 \\
\hline $\mathbf{t}(\mathbf{4})$ & .043075 & 0.73225 \\
\hline p-level & .967706 & .50461 \\
\hline
\end{tabular}

An estimated value of the coefficient $\eta(0.060525)$ describes convergent movement of the total consumption expenditure made by a visitor in France in the observed period.

Table 8. The estimated model (11): Italy, 2012-2018.

$\mathrm{R}=0.43892$ Variance explained: $19.265 \%$

\begin{tabular}{|l|r|r|}
\cline { 2 - 3 } \multicolumn{1}{c|}{} & \multicolumn{1}{c|}{$\boldsymbol{\eta}$} & \multicolumn{1}{c|}{$\boldsymbol{v}$} \\
\hline Estimate & 1.646642 & -.813356 \\
\hline Std. Err. & .414684 & .499291 \\
\hline $\mathbf{t}(\mathbf{4})$ & 3.970834 & -1.629023 \\
\hline $\mathbf{p}$-level & .016527 & .178640 \\
\hline
\end{tabular}

The total consumption visitor expenditure was increased from 17576835.69 to 26829423.58 (unit of measure: Thousand euro) in the period 2012-2018 in Italy. 
According to the logistic equation, for $1<\eta<2$ all solutions monotonically increase to $z=(\eta-1) / \eta$, or $(1.646642-1) / 1.646642=0.392704$.

According to (10.), the value of the total consumption visitor expenditure monotonically increases to 0.392704 / $(0.813356 / 1.646642)$ or $0.392704 / 0.493948$ or 0,795031 or 21330222.9971 (unit of measure: Thousand euro) in Italy.

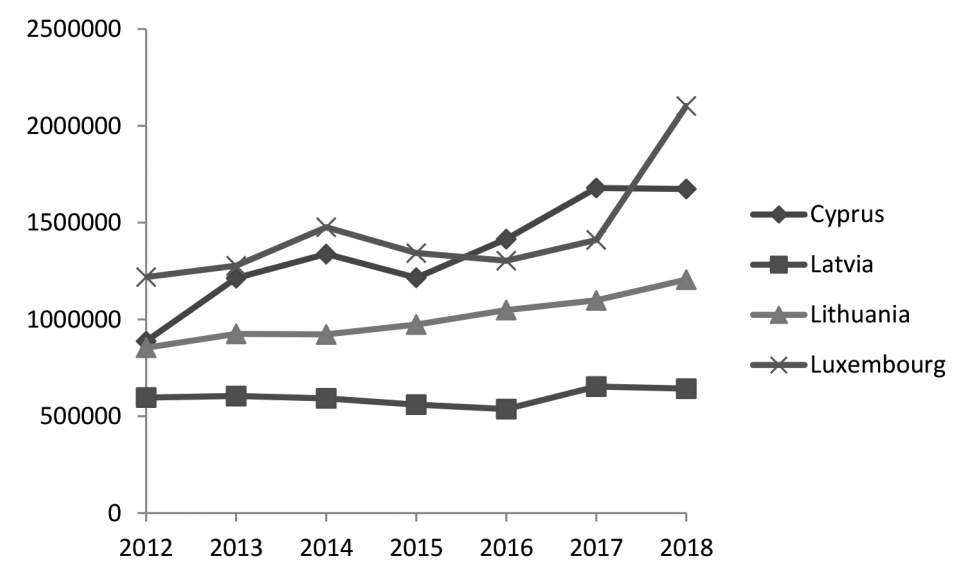

Figure 3. The total consumption expenditure made by a visitor or on behalf of a visitor for and during his/her trip and stay at destination (thousand euro): Cyprus, Latvia, Lithuania, Luxembourg, 2012-2018.

Source : https://ec.europa.eu/eurostat/databrowser/view/tin00194/default/table?lang=en

Table 9. The estimated model (11): Cyprus, 2012-2018. $\mathrm{R}=0.72753$ Variance explained: $52.936 \%$

\begin{tabular}{|l|r|r|}
\cline { 2 - 3 } \multicolumn{1}{c|}{} & \multicolumn{1}{c|}{$\boldsymbol{\eta}$} & \multicolumn{1}{c|}{$\boldsymbol{v}$} \\
\hline Estimate & 1.57114 & -.592560 \\
\hline Std. Err. & .310382 & .373612 \\
\hline $\mathbf{t}(\mathbf{4})$ & 5.061968 & -1.586031 \\
\hline p-level & .00717 & .187917 \\
\hline
\end{tabular}

The total consumption visitor expenditure was increased from 887872.5 to 1679033.62 (unit of measure: Thousand euro) in the period 2012-2018 in Cyprus.

According to the logistic equation, for $1<\eta<2$ all solutions monotonically increase to $z=(\eta-1) / \eta$, or $(1.57114-1) / 1.57114=0.363519$.

According to (10.), the value of the total consumption visitor expenditure monotonically increases to $0.363519 /(0.59256 / 1.57114)$ or $0.363519 / 0.377153$ or 0,963850 or 1618336.5546 (unit of measure: Thousand euro) in Cyprus.

Table 10. The estimated model (11): Latvia, 2012-2018.

\begin{tabular}{|l|r|r|}
\cline { 2 - 3 } \multicolumn{1}{c|}{} & \multicolumn{1}{c|}{$\boldsymbol{\eta}$} & \multicolumn{1}{c|}{$\boldsymbol{v}$} \\
\hline Estimate & 1.646642 & -.813356 \\
\hline Std. Err. & .414684 & .499291 \\
\hline $\mathbf{t}(\mathbf{1 8})$ & 3.970834 & -1.629023 \\
\hline p-level & .016527 & .178640 \\
\hline
\end{tabular}


The total consumption visitor expenditure was increased from 537344.47 to 653645.88 (unit of measure: Thousand euro) in the period 2012-2018 in Latvia.

According to the logistic equation, for $1<\eta<2$ all solutions monotonically increase to $z=(\eta-1) / \eta$, or $(1.763687-1) / 1.763687=0.433006$.

According to (10.), the value of the total consumption visitor expenditure monotonically increases to $0.433006 /(0.827290 / 1.763687)$ or $0.433006 / 0.469068$ or 0,9231199 or 603393.5194 (unit of measure: Thousand euro) in Latvia.

Table 11. The estimated model (11): Lithuania, 2012-2018.

$\mathrm{R}=0.95511$ Variance explained: $91.223 \%$

\begin{tabular}{|l|r|r|}
\cline { 2 - 3 } \multicolumn{1}{c|}{} & \multicolumn{1}{c|}{$\boldsymbol{\eta}$} & \multicolumn{1}{c|}{ v } \\
\hline Estimate & .929166 & .161774 \\
\hline Std. Err. & .183802 & .224341 \\
\hline p-level & 5.055249 & .721107 \\
\hline
\end{tabular}

An estimated value of the coefficient $\eta(0.929166)$ describes convergent movement of the total consumption expenditure made by a visitor in Lithuania in the observed period.

Table 12. The estimated model (11): Luxembourg, 2012-2018. $\mathrm{R}=0.35926$ Variance explained: $12.907 \%$

\begin{tabular}{|l|r|r|}
\cline { 2 - 3 } \multicolumn{1}{c|}{} & \multicolumn{1}{c|}{$\boldsymbol{\eta}$} & \multicolumn{1}{c|}{ v } \\
\hline Estimate & 1.084001 & .041183 \\
\hline Std. Err. & 1.552167 & 2.414167 \\
\hline $\mathbf{t}(4)$ & .698379 & .017059 \\
\hline p-level & .523411 & .987207 \\
\hline
\end{tabular}

The total consumption visitor expenditure was increased from 1219069.32 to 2102886.36 (unit of measure: Thousand euro) in the period 2012-2018 in Luxembourg.

According to the logistic equation, for $1<\eta<2$ all solutions monotonically increase to $\mathrm{z}=(\eta-1) / \eta$, or $(1.084001-1) / 1.084001=0.077492$.

According to (10.), the value of the total consumption visitor expenditure monotonically increases to 0.077492 / $(0.041183 / 1.084001)$ or $0.077492 / 0.03799$ or 2.0398 or 4289467.597 (unit of measure: Thousand euro) in Luxembourg.

Table 13. The estimated model (11): Malta, 2012-2018. $\mathrm{R}=0.72994$ Variance explained: $53.281 \%$

\begin{tabular}{|l|r|r|}
\cline { 2 - 3 } \multicolumn{1}{c|}{} & \multicolumn{1}{c|}{$\boldsymbol{\eta}$} & \multicolumn{1}{c|}{$\boldsymbol{v}$} \\
\hline Estimate & 1.21985 & -.158442 \\
\hline Std. Err. & .474587 & .653608 \\
\hline $\mathbf{t}(4)$ & 2.568941 & -.242411 \\
\hline p-level & .062048 & .820384 \\
\hline
\end{tabular}


The total consumption visitor expenditure was increased from 334218.43 to 605973.05 (unit of measure: Thousand euro) in the period 2012-2018 in Malta.

According to the logistic equation, for $1<\eta<2$ all solutions monotonically increase to $z=(\eta-1) / \eta$, or $(1.21985-1) / 1.21985=0.180227$.

According to (10.), the value of the total consumption visitor expenditure monotonically increases to 0.180227 / ( $0.158442 / 1.21985)$ or $0.180227 / 0.129886$ or 1.387578 or 840834,8728 (unit of measure: Thousand euro) in Malta.

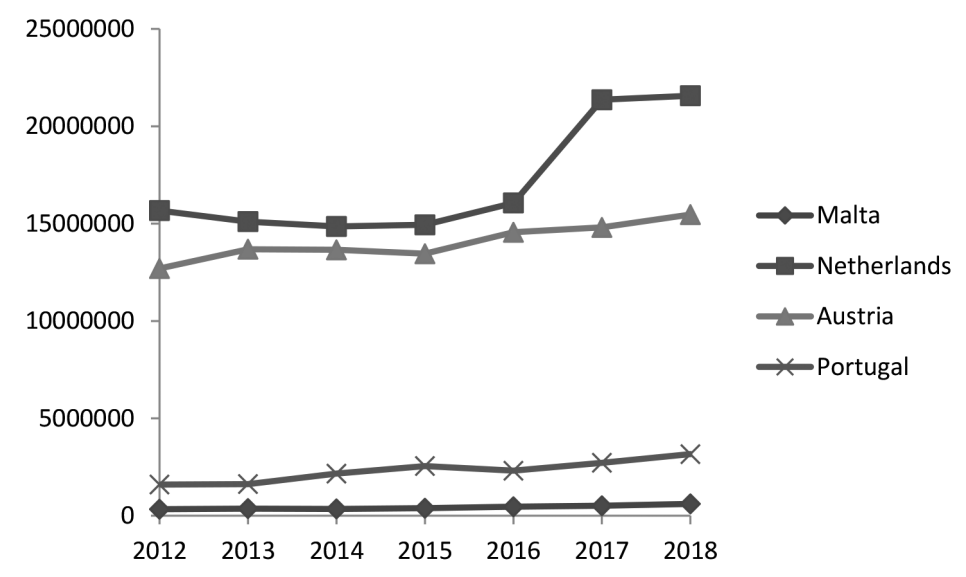

Figure 4. The total consumption expenditure made by a visitor or on behalf of a visitor for and during his/her trip and stay at destination (thousand euro): Malta, Netherlands, Austria, Portugal, 2012-2018.

Source : https://ec.europa.eu/eurostat/databrowser/view/tin00194/default/table?lang=en

Table 14. The estimated model (11): Netherlands, 2012-2018.

$\mathrm{R}=0.74113$ Variance explained: $54.928 \%$

\begin{tabular}{|l|r|r|}
\cline { 2 - 3 } \multicolumn{1}{c|}{} & \multicolumn{1}{c|}{$\boldsymbol{\eta}$} & \multicolumn{1}{c|}{$\boldsymbol{v}$} \\
\hline Estimate & 1.17404 & -.0146673 \\
\hline Std. Err. & .381200 & .476349 \\
\hline p-level & 3.079852 & -.307912 \\
\hline
\end{tabular}

The total consumption visitor expenditure was increased from 14855688.06 to 21566507.88 (unit of measure: Thousand euro) in the period 2012-2018 in the Netherlands.

According to the logistic equation, for $1<\eta<2$ all solutions monotonically increase to $\mathrm{z}=(\eta-1) / \eta$, or $(1.17404-1) / 1.17404=0.148240$.

According to (10.), the value of the total consumption visitor expenditure monotonically increases to 0.14824 / ( $(0.146673 / 1.17404)$ or $0.14824 / 0.124930$ or 1.1865845 or 25590494.7528 (unit of measure: Thousand euro) in the Netherlands. 
Table 15. The estimated model (11): Austria, 2012-2018.

$\mathrm{R}=0.75983$ Variance explained: $57.735 \%$

\begin{tabular}{|l|r|r|}
\cline { 2 - 3 } \multicolumn{1}{c|}{} & \multicolumn{1}{c|}{$\boldsymbol{\eta}$} & \multicolumn{1}{c|}{$\boldsymbol{v}$} \\
\hline Estimate & 1.254206 & -.246688 \\
\hline Std. Err. & .340407 & .378777 \\
\hline $\mathbf{t}(\mathbf{4})$ & 3.684427 & -.651276 \\
\hline p-level & .021122 & .550391 \\
\hline
\end{tabular}

The total consumption visitor expenditure was increased from 12696610.95 to 15464412.12 (unit of measure: Thousand euro) in the period 2012-2018 in Austria.

According to the logistic equation, for $1<\eta<2$ all solutions monotonically increase to $\mathrm{z}=(\eta-1) / \eta$, or $(1.254206-1) / 1.254206=0.202683$.

According to (10.), the value of the total consumption visitor expenditure monotonically increases to 0.202683 / $(0.246688 / 1.254206)$ or $0.202683 / 0.196688$ or 1.03048 or 15935767.4014 (unit of measure: Thousand euro) in Austria.

Table 16. The estimated model (11): Portugal, 2012-2018. $\mathrm{R}=0.82235$ Variance explained: $67.626 \%$

\begin{tabular}{|l|r|r|}
\cline { 2 - 3 } \multicolumn{1}{c|}{} & \multicolumn{1}{c|}{$\boldsymbol{\eta}$} & \multicolumn{1}{c|}{$\boldsymbol{v}$} \\
\hline Estimate & 1.350419 & -.323554 \\
\hline Std. Err. & .380197 & .511697 \\
\hline p-level & 3.551896 & -.632315 \\
\hline
\end{tabular}

The total consumption visitor expenditure was increased from 1598984.38 to 3163662.62 (unit of measure: Thousand euro) in the period 2012-2018 in Portugal.

According to the logistic equation, for $1<\eta<2$ all solutions monotonically increase to $z=(\eta-1) / \eta$, or $(1.350419-1) / 1.350419=0.259489$.

According to (10.), the value of the total consumption visitor expenditure monotonically increases to 0.259489 / $(0.323554 / 1.350419)$ or $0.259489 / 0.239595$ or 1.083032 or 3426347.85 (unit of measure: Thousand euro) in Portugal.

Table 17. The estimated model (11): Slovenia, 2012-2018.

$\mathrm{R}=0.90604$ Variance explained: $82.091 \%$

\begin{tabular}{|l|r|r|}
\cline { 2 - 3 } \multicolumn{1}{c|}{} & \multicolumn{1}{c|}{$\boldsymbol{\eta}$} & \multicolumn{1}{c|}{$\boldsymbol{v}$} \\
\hline Estimate & .385590 & .85367 \\
\hline Std. Err. & .406368 & .50810 \\
\hline t(4) & .963088 & 1.68012 \\
\hline p-level & .390042 & .16823 \\
\hline
\end{tabular}

An estimated values of the coefficient $\eta(0.385590)$ describes convergent movement of the total consumption expenditure made by a visitor in Slovenia in the observed period. 


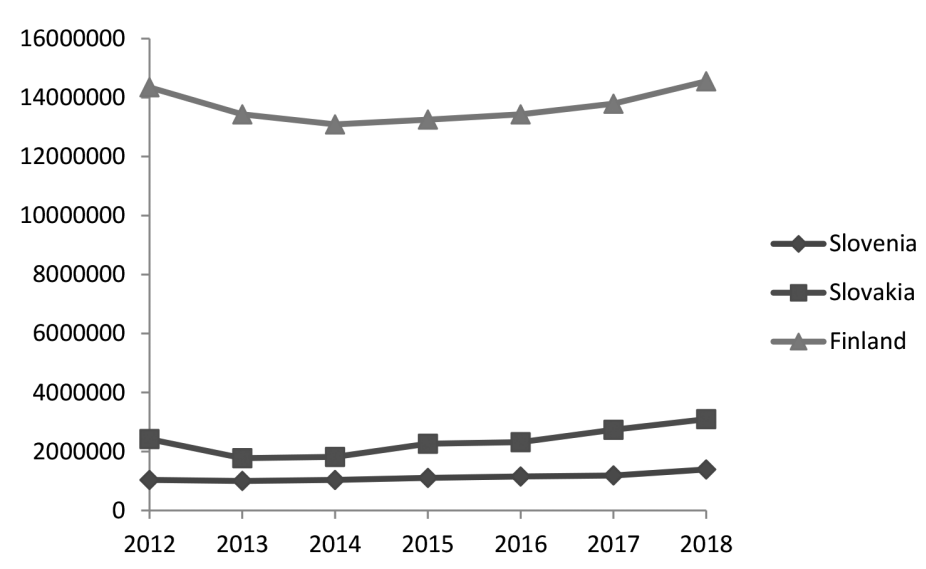

Figure 5. The total consumption expenditure made by a visitor or on behalf of a visitor for and during his/her trip and stay at destination (thousand euro): Slovenia, Slovakia, Finland, 2012-2018.

Source : https://ec.europa.eu/eurostat/databrowser/view/tin00194/default/table?lang=en

Table 18. The estimated model (11): Slovakia, 2012-2018.

\begin{tabular}{|l|r|r|}
\multicolumn{1}{c|}{$\mathrm{R}=0.60168$} & Variance explained: $36.202 \%$ \\
\cline { 2 - 3 } \multicolumn{1}{c|}{} & \multicolumn{1}{c|}{$\boldsymbol{\eta}$} & \multicolumn{1}{c|}{$\boldsymbol{v}$} \\
\hline Estimate & 1.197966 & -.202332 \\
\hline Std. Err. & .607917 & .803485 \\
\hline t(4) & 1.970607 & -.251818 \\
\hline p-level & .120086 & .813591 \\
\hline
\end{tabular}

The total consumption visitor expenditure was increased from 1774526.52 to 3096449.72 (unit of measure: Thousand euro) in the period 2012-2018 in Slovakia.

According to the logistic equation, for $1<\eta<2$ all solutions monotonically increase to $\mathrm{z}=(\eta-1) / \eta$, or $(1.197966-1) / 1.197966=0.165252$.

According to (10.), the value of the total consumption visitor expenditure monotonically increases to $0.165252 /(0.202332 / 1.197966)$ or $0.165252 / 0.168896$ or 0.978425 or 3029643.8173 (unit of measure: Thousand euro) in Slovakia.

Table 19. The estimated model (11): Finland, 2012-2018.

$\mathrm{R}=0.47489$ Variance explained: $22.552 \%$

\begin{tabular}{|l|r|r|}
\cline { 2 - 3 } \multicolumn{1}{c|}{} & \multicolumn{1}{c|}{$\boldsymbol{\eta}$} & \multicolumn{1}{c|}{$\boldsymbol{v}$} \\
\hline Estimate & 2.474344 & -1.551351 \\
\hline Std. Err. & .476461 & .501290 \\
\hline $\mathbf{t}(\mathbf{4})$ & 5.193176 & -3.094681 \\
\hline p-level & .006547 & .036408 \\
\hline
\end{tabular}

The total consumption visitor expenditure fluctuated between 13091585.35 and 14552001.54 (unit of measure: Thousand euro) in the period 2012-2018 in Finland.

According to the logistic equation, for $2<\eta<3$ fluctuations converge to $z=(\eta-1) / \eta$, or $(2.474344-1) / 2.474344=0.595852$. 
According to (10.), the equilibrium value of the total consumption visitor expenditure was $0.595852 /(1.551351 / 2.474344)$ or $0.595852 / 0.626975$ or 0.950360 or 13829640.1835 (unit of measure: Thousand euro) in Finland in the observed period.

\section{CONCLUSION}

This paper creates the total consumption visitor expenditure growth model. For most choices of $\alpha, \beta, \gamma, \varepsilon$, and g there is no explicit solution for the growth model (11). Namely, knowing $\alpha, \beta, \gamma$, $\varepsilon$, and g and measuring $\mathrm{e}_{0}$ would not suffice to predict $\mathrm{e}_{\mathrm{t}}$ for any point in time, as was previously possible.

A key hypothesis of this work is based on the idea that the coefficient

$$
\eta=\left(\frac{\beta+\gamma}{1-g}\right)
$$

plays a crucial role in explaining the local growth stability of the total consumption visitor expenditure, where , $\beta$ - the investment rate, g- the government expenditure rate, $\gamma$ - the net exports rate.

An estimated values of the coefficient $\eta$ confirm stable growth of the total consumption expenditure made by a visitor in Greece, Spain, Italy, Cyprus, Latvia, Luxembourg, Malta, Netherlands, Austria, Portugal and Slovakia in the observed period.

An estimated values of the coefficient $\eta$ show convergent fluctuation of the total consumption expenditure made by a visitor in Belgium and Finland in the observed period.

An estimated values of the coefficient $\eta$ describe convergent movement of the total consumption expenditure made by a visitor in Estonia, Ireland, France, Lithuania, and Slovenia in the observed period.

In this sense, tourism has the potential to increase the aggregate demand in the euro area.

\section{REFERENCES}

Benhabib, J., Day, R.H. (1981) Rational Choice and Erratic Behaviour, Review of Economic Studies 48: 459-471.

Benhabib, J., Day, R.H. (1982) Characterization of Erratic Dynamics in the Overlapping Generation Model. Journal of Economic Dynamics and Control 4: 37-55.

Day, R.H. (1982) Complex Economic Dynamics: Obvious in History, Generic in Theory, Elusive in Data. Journal of Applied Econometrics, Vol. 7, Issue Supplement, 1992, S9-S23.

Day, R.H. (1982) Irregular Growth Cycles. American Economic Review 72: 406-414.

Day, R.H. (1983) The Emergence of Chaos from Classica Economic Growth. Quarterly Journal of Economics 98: 200-213.

Day, R.H. (1997) Complex Economic Dynamics. Volume I: "An introduction to dynamical systems and market mechanism", MIT Press, In: Discrete Dynamics in Nature and Society, Vol. 1. 177-178.

Goodwin, R.M. (1990) Chaotic Economic Dynamics. Clarendon Press, Oxford.

Grandmont, J.M. (1985) On Endogenous Competitive Business Cycles. Econometrica 53: 994-1045. 
Jablanovic, V. (2011) Budget Deficit and Chaotic Economic Growth Models. Aracne editrice S.r.1, Roma.

Jablanovic, V. (2013) Elements of Chaotic Microeconomics. Aracne editrice S.r.l., Roma.

Jablanovic, V. (2016) A Contribution to the Chaotic Economic Growth Theory. Aracne editrice S.r.l., Roma.

Jablanovic, V. (2018). The Chaotic Growth Model of the International Tourism Receipts: Euro Area. In Proceedings of Second International Scientific Conference EMAN 2018 Economics \& Management: How to Cope With Disrupted Times (pp. 703-717). Ljubljana.

Li, T., Yorke, J. (1975) Period Three Implies Chaos. American Mathematical Monthly 8: 985-992.

Lorenz, E.N. (1963) Deterministic nonperiodic flow. Journal of Atmospheric Sciences 20: 130-141.

Lorenz, H.W. (1993) Nonlinear Dynamical Economics and Chaotic Motion. 2nd edition, Springer-Verlag, Heidelberg.

May, R.M. (1976) Mathematical Models with Very Complicated Dynamics. Nature 261: 459-467.

Medio, A. (1993) Chaotic Dynamics: Theory and Applications to Economics. Cambridge University Press, Cambridge.

Medio, A. (1996) Chaotic dynamics. Theory and applications to economics. Cambridge University Press, In: De Economist 144 (4), 695-698. https://ec.europa.eu/eurostat/databrowser/view/ tin00194/default/table?lang=en 